\title{
Physical Signs of Dehydration in the Elderly
}

\author{
Miyuki Shimizu ${ }^{1}$, Kensuke Kinoshita ${ }^{2}$, Kazuya Hattori ${ }^{2}$, Yoshio Ota ${ }^{2}$, \\ Takao Kanai ${ }^{2}$, Hiroyuki Kobayashi ${ }^{2}$ and Yasuharu Tokuda ${ }^{2}$
}

\begin{abstract}
Objective Dehydration is a common condition and frequent cause of hospitalization in older people, despite the caregiver's high attention in attempt to avoid its occurrence. In this study, various physical signs were examined as clinical signs of dehydration in elderly.

Methods A prospective observational study was conducted in an acute care teaching hospital. Consecutive elderly patients who were admitted to the Department of Medicine were evaluated. Dehydration was defined as a calculated serum osmolality above $295 \mathrm{mOsm} / \mathrm{L}$. The patients diagnosed as dehydrated or not dehydrated were observed for physical signs of dehydration. Data of blood and urine chemistry analysis were also compared between the two groups.

Results A total of 27 elderly patients admitted with acute medical conditions were included in this study. For the physical signs, dry axilla had moderate sensitivity (44\%) and excellent specificity (89\%) to detect dehydration. Sunken eyes and delayed capillary refill time also showed relatively good specificity (83\%). For laboratory data, the mean concentrations of serum sodium of the dehydrated group $(146 \mathrm{mEq} / \mathrm{L})$ was significantly higher $(\mathrm{p}<0.01)$ than those of the non-dehydrated group $(134 \mathrm{mEq} / \mathrm{L})$.

Conclusion Physical signs of dehydration in elderly showed relatively good specificity but poor sensitivity. The evaluation of the axillary moisture could help assess dehydration as well as laboratory data analysis such as serum sodium concentration.
\end{abstract}

Key words: physical sign, dehydration, elderly, dry axilla

(Intern Med 51: 1207-1210, 2012)

(DOI: 10.2169/internalmedicine.51.7056)

\section{Introduction}

Dehydration is a common condition in the elderly and exposes them to the risks of acute confusional states, delirium, renal failure, infection, falls, pressure ulcers and constipation $(1,2)$. The syndrome of dehydration is paid attention by their caregivers. Data from Medicare Provider Analysis and Review files compiled in 1991 by the Health Care Financing Administration (HCFA), identified dehydration as one of the 10 most common diagnoses reported for Medicare Hospitalization (3). Even in 2009, dehydration was listed as one of the 20 most common diagnoses reported by Agency for Healthcare Research and Quality (AHRQ).

The reason why the incidence of dehydration has not decreased in over a decade is that the means to recognize the symptoms of dehydration is not familiar to family members and care persons at home and there are also difficulties in determining dehydration even in nursing home residents. The common physical signs of dehydration are dry axilla (1), dry mouth, sunken eyes, decreased skin turgor, and delayed capillary refill time (4). These symptoms can be routinely identified by healthcare professionals, however they are not easily noticed by care persons at home and nursing homes.

In this study, we evaluated the relations between various physical signs and blood and urine test results, and revealed the most appropriate physical signs to determine dehydration in elders.

${ }^{1}$ Terumo Corporation R\&D Headquarters, Japan and ${ }^{2}$ Department of Medicine, Mito Kyodo General Hospital, University of Tsukuba, Japan Received for publication December 6, 2011; Accepted for publication January 29, 2012

Correspondence to Dr. Yasuharu Tokuda, yasuharu.tokuda@gmail.com 
Table 1. Age and Condition at Discharge of 27 Elderly Patients

\begin{tabular}{ccccc}
\hline & No. & Age & $\begin{array}{c}\text { Alive or Dead at discharge } \\
\text { Alive/Dead }\end{array}$ \\
\hline $\begin{array}{c}\text { Dehydrated } \\
\text { group }\end{array}$ & male & 6 & $84.0 \pm 4.6$ & $5 / 1$ \\
female & 3 & $85.7 \pm 9.1$ & $0 / 3$ \\
$\begin{array}{c}\text { Non-dehydrated } \\
\text { group }\end{array}$ & male & 10 & $83.3 \pm 6.4$ & $8 / 2$ \\
\hline
\end{tabular}

\section{Materials and Methods}

\section{Subjects and setting}

We studied patients aged 65 or older who presented to an acute care teaching hospital (Mito Kyodo General Hospital, Mito City, Ibaraki, Japan) and were consecutively admitted to the Department of Medicine with acute medical conditions. We conducted a prospective study over a seven-month span from December 2011. Patients excluded from the study were those with chronic kidney disease. Mito Kyodo General Hospital Ethics Committee approved the protocol. Research staff obtained written informed consent to participate in the current study from patients who were able to provide informed consent or from their designated representatives (if patients were unable to provide consent).

\section{Methods}

Subjects were classified as dehydrated or not dehydrated according to the criteria of calculated serum osmolality above $295 \mathrm{mOsm} / \mathrm{L}$. The term of dehydration refers to losses of intracellular water that ultimately cause cellular desiccation and elevation of the serum osmolality (4). Thus, as a measure of dehydration, elevated serum osmolality was used in this study.

In the initial process of the evaluation, each patient was observed to have physical signs of dehydration as dry axilla, dry mouth, decreased skin turgor, sunken eyes, and delayed capillary refill time. These physical signs were taken by internal medicine residents. Conscioussness level, dry mouth, dry axilla, sunken eyes, decreased skin turgor, and delayed capillary time were examined and recorded. Dry mouth was considered as present when both mucous membrane and tongue were dry by inspection. Dry axilla was examined by palpating bilateral axillary skin using the examiner's second to fifth fingers. Sunken eyes were considered to be present when the bilateral eyeballs seemed abnormally sunken. Decreased skin turgor referred the slow return of skin to its normal position after being pinched between the examiner's thumb and forefinger. Capillary refill time was determined by compressing the distal phalanx of the patient's middle finger, positioned level with the heart, for 5 seconds and then timing the return of normal color to the finger. The up- per limit of normal refill time was set at 2 seconds (4).

Next, the blood samples of the patient were obtained for blood tests as total protein concentration (TP), albumin concentration (ALB), blood urea nitrogen concentration (BUN), creatinine concentration $(\mathrm{Cr})$, uric acid concentration (UA), sodium concentration $\left(\mathrm{Na}^{+}\right)$, serum osmolality, and blood glucose concentration (BG). A BUN: Cr ratio (BUN/Cr) and osmolality were calculated. Osmolality was calculated with the following equation:

Calculated osmolality $=2 \times \mathrm{Na}^{+}+\mathrm{BG} / 18+\mathrm{BUN} / 2.8$

The urine sample of patient was then obtained for the urine tests as sodium concentration $\left(\mathrm{Na}^{+}\right)$, creatinine concentration $(\mathrm{Cr})$, and osmolality. The observation of physical signs, blood tests, urine tests were performed several times during hospitalization.

\section{Statistical analysis}

The statistical analysis was carried out with Student's unpaired $t$ test or an analysis of variance (ANOVA) using the SPSS version 18.0 for Windows (SAS Institute, Cary, NC, USA) when appropriate. A two-tailed $P$ value of less than 0.05 was regarded as significant.

\section{Results}

\section{Patients}

Twenty-seven patients (16 men and 11 women) were recruited in the study sample. The patients diagnosed as dehydrated were 6 males aged $84.0 \pm 4.6$ and 4 females aged $85.7 \pm 9.1$. The patients diagnosed as non-dehydrated were 10 males aged $83.3 \pm 6.4$ and 8 females aged $89.5 \pm 5.3$ (Table 1). In the dehydrated group, the chief complaints were fever, dyspnea, diarrhea, anorexia, edema, abdominal pain, and dizziness. In the non-dehydrated group, the chief complaints were fever (10 patients), liver dysfunction (2 patients), and others (dyspnea, vomitting, disturbance of consciousness, cough, hemiplegia, and fatigue). During the hospitalization, $44 \%$ of patients in the dehydrated group died, while $17 \%$ in the non-dehydrated group died.

\section{Physical signs}

The prevalence of patients with positive physical signs of dehydration is shown in Table 2. The number of patients with decreased consciousness level was 1 for dehydrated, and 5 for non-dehydrated groups. Dry axilla was observed in 4 patients for the dehydrated group and 2 patients for the non-dehydrated group. Dry mouth was observed in about half of the patients in each group. Delayed capillary refill time and sunken eyes were observed in several patients of both groups. Decreased skin turgor was noted in 2 and 5 patients of the dehydrated and non-dehydrated groups, respectively.

Sensitivity was high in both dry axilla and dry mouth, while decreased consciousness level, sunken eyes, decreased skin turgor, and delayed capillary refill time were compara- 
Table 2. Physical Signs Observed in Dehydrated and Non-dehydrated Groups. the Number of Patients Showing Each Physical Sign, and the Sensitivity, Specificity, and Odds Ratio for Each Physical Sign are Indicated

\begin{tabular}{|c|c|c|c|c|c|c|c|c|}
\hline & No. & & $\begin{array}{c}\text { decreased } \\
\text { conciousness } \\
\text { level }\end{array}$ & dry axilla & dry mouth & sunken eyes & $\begin{array}{l}\text { decreased } \\
\text { skin turgor }\end{array}$ & $\begin{array}{c}\text { delayed } \\
\text { capillary } \\
\text { refill time }\end{array}$ \\
\hline $\begin{array}{l}\text { Dehydrated } \\
\text { group }\end{array}$ & 9 & physical sign $(+)$ & 1 & 4 & 5 & 2 & 2 & 2 \\
\hline \multirow[t]{4}{*}{$\begin{array}{l}\text { Non-dehydrated } \\
\text { group }\end{array}$} & 18 & physical sign $(+)$ & 5 & 2 & 7 & 3 & 5 & 3 \\
\hline & & sensitivity & $11 \%$ & $44 \%$ & $56 \%$ & $22 \%$ & $22 \%$ & $22 \%$ \\
\hline & & specificity & $72 \%$ & $89 \%$ & $61 \%$ & $83 \%$ & $72 \%$ & $83 \%$ \\
\hline & & odds ratio & 0.4 & 4.0 & 1.4 & 1.3 & 0.8 & 1.3 \\
\hline
\end{tabular}

Table 3. The Mean Value of the Clinical Examination in Each Group is Indicated. $\mathrm{Na}^{+}$, Osmolality Showed a Significant Difference between Two Groups in Blood Tests, Whereas No Index in Urine Tests Showed a Significant Difference

\begin{tabular}{ccccccc}
\hline & Blood tests & & & & & \\
\hline & $\begin{array}{c}\mathrm{TP} \\
(\mathrm{g} / \mathrm{dL})\end{array}$ & $\begin{array}{c}\mathrm{ALB} \\
(\mathrm{g} / \mathrm{dL})\end{array}$ & $\mathrm{BUN} / \mathrm{Cr}$ & $\begin{array}{c}\mathrm{UA} \\
(\mathrm{mg} / \mathrm{dL})\end{array}$ & $\begin{array}{c}\mathrm{Na}+ \\
(\mathrm{mEq} / \mathrm{L})\end{array}$ & $\begin{array}{c}\text { Osmolality } \\
(\mathrm{mmOsm})\end{array}$ \\
\hline \hline $\begin{array}{c}\text { Dehydrated } \\
\text { group }\end{array}$ & 6.8 & 3.2 & 27 & 6.8 & 146.3 & 309.6 \\
$\begin{array}{c}\text { Non-dehydrated } \\
\text { group }\end{array}$ & 7.0 & 3.3 & 24 & 5.3 & 134.4 & 279.0 \\
& $\mathrm{p}=0.27$ & $\mathrm{p}=0.34$ & $\mathrm{p}=0.20$ & $\mathrm{p}=0.09$ & $\mathrm{p}<0.01$ & $\mathrm{p}<0.05$ \\
\hline
\end{tabular}

\begin{tabular}{cccc}
\hline \multicolumn{3}{c}{ Urine tests } & \\
\hline & $\begin{array}{c}\mathrm{Na}+ \\
(\mathrm{mEq} / \mathrm{L})\end{array}$ & $\begin{array}{c}\mathrm{Cr} \\
(\mathrm{mg} / \mathrm{dL})\end{array}$ & $\begin{array}{c}\text { Osmolality } \\
(\mathrm{mmOsm})\end{array}$ \\
\hline $\begin{array}{c}\text { Dehydrated } \\
\text { group }\end{array}$ & 79.5 & 68.5 & 558.4 \\
$\begin{array}{c}\text { Non-dehydrated } \\
\text { group }\end{array}$ & 93.5 & 101.3 & 468.0 \\
& $\mathrm{p}=0.45$ & $\mathrm{p}=0.39$ & $\mathrm{p}=0.10$ \\
\hline
\end{tabular}

TP:Total protein, ALB: Albumin, BUN: Blood urea nitrogen, Cr: Creatinine, UA: Uric acid

tively low. The specificity of dry axilla was the highest (89\%), and sunken eyes and delayed capillary refill time were the second highest (83\%). Odds ratio of dry axilla was the highest (4.0) among all physical findings.

\section{Clinical examination for the dehydrated and the non-dehydrated groups}

The results of clinical examination for both groups are shown in Table 3. For the blood tests, TP and ALB of the dehydrated group were slightly lower $(6.8 \mathrm{mg} / \mathrm{dL}$ and 3.2 $\mathrm{mg} / \mathrm{dL}$, respectively) than those $(7.0 \mathrm{mg} / \mathrm{dL}$ and $3.3 \mathrm{mg} / \mathrm{dL}$, respectively) in the non-dehydrated group. The average $\mathrm{BUN} / \mathrm{Cr}$ ratio was 28 for the dehydrated group and 24 for the non-dehydrated group. The concentration of uric acid for the dehydrated group was $6.8 \mathrm{mg} / \mathrm{dL}$ higher than that of the non-dehydrated group was $5.3 \mathrm{mg} / \mathrm{dL}$. And also the concentration of serum sodium for the dehydrated group was 146.3 $\mathrm{mEq} / \mathrm{L}$ as compared with the non-dehydrated group (134.7 $\mathrm{mEq} / \mathrm{L}, \mathrm{p}<0.01)$. Serum measured osmolality for the dehydrated group was significantly higher than that for the nondehydrated group.

\section{Correlation between clinical examination and dry axilla}

The correlation between clinical examination and dry axilla is shown in Table 4 . TP with dry axilla $(7.0 \mathrm{mg} / \mathrm{dL})$ was significantly higher than that with wet axilla $(6.5 \mathrm{mg} / \mathrm{dL})$, whereas ALB with dry axilla was significantly lower. BUN/ $\mathrm{Cr}$ ratio was 40 for dry axilla and 25 for wet axilla. The os- molality for dry axilla (307.8 mmOsm) was significantly higher than that for wet axilla (289.5 mmOsm). However, there were no significant differences between two groups for urine tests.

\section{Discussion}

In the present study, we demonstrated that the physical signs could indicate the dehydration state. There were significant correlations between dry axilla and laboratory test results such as TP, ALB, BUN/Cr ratio and serum osmolality.

It has been reported that $10 \%$ of the geriatric patients admitted to long term care hospitals in Japan have low to moderate levels of dehydration in addition to other apparent disease conditions (5). This suggests that dehydration may not be easily found out even if caretakers pay attention to dehydration. Dehydration is the result of a fluid imbalance and inadequate circulating volume from either the consumption of too little fluid associated with the lack of thirst or due to a loss of too much fluid associated with the lack of condensation ability of urine in kidney (3). This results in the increase in plasma sodium concentration, serum osmolality, and capillary refill time. This also affects the ability of sweating (6) and saliva production. The degree of dehydration is correlated with changes in signs and symptoms classified as mild to severe dehydration.

In all patients, the most frequent main complaint was fever. One of the symptoms in moderate dehydration was fe- 
Table 4. The Mean Values of the Clinical Examination in Those with Dry Axilla and Wet Axilla are Indicated. TP, ALB, BUN/Cr ratio, and Osmolality Showed Significant Differences between the Two Groups in Blood Tests, Whereas No Index in Urine Tests Showed a Significant Difference

\begin{tabular}{|c|c|c|c|c|c|c|c|c|c|c|}
\hline \multicolumn{7}{|c|}{ Blood tests } & \multicolumn{4}{|c|}{ Urine tests } \\
\hline & $\begin{array}{c}\mathrm{TP} \\
(\mathrm{g} / \mathrm{dL})\end{array}$ & $\begin{array}{l}\text { ALB } \\
(\mathrm{g} / \mathrm{dL})\end{array}$ & $\mathrm{BUN} / \mathrm{Cr}$ & $\begin{array}{c}\text { UA } \\
(\mathrm{mg} / \mathrm{dL})\end{array}$ & $\begin{array}{c}\mathrm{Na}+ \\
(\mathrm{mEq} / \mathrm{L})\end{array}$ & $\begin{array}{l}\text { Osmolality } \\
(\mathrm{mmOsm})\end{array}$ & & $\begin{array}{c}\mathrm{Na}+ \\
(\mathrm{mEq} / \mathrm{L}) \\
\end{array}$ & $\begin{array}{c}\mathrm{Cr} \\
(\mathrm{mg} / \mathrm{dL})\end{array}$ & $\begin{array}{l}\text { Osmolality } \\
\text { (mmOsm) }\end{array}$ \\
\hline Dry axilla & 7.0 & 2.7 & 40 & 5.1 & 145.1 & 307.8 & Dry axilla & 75.0 & 78.8 & 549.5 \\
\hline \multirow[t]{2}{*}{ Wet axilla } & 6.5 & 3.1 & 25 & 5.5 & 137.6 & 289.5 & Wet axilla & 98.2 & 66.1 & 511.9 \\
\hline & $\mathrm{p}<0.05$ & $\mathrm{p}<0.05$ & $\mathrm{p}<0.05$ & $\mathrm{p}=0.36$ & $\mathrm{p}=0.06$ & $\mathrm{p}<0.05$ & & $\mathrm{p}=0.22$ & $\mathrm{p}=0.35$ & $\mathrm{p}=0.21$ \\
\hline
\end{tabular}

TP:Total protein, ALB: Albumin, BUN: Blood urea nitrogen, Cr: Creatinine, UA: Uric acid

ver. However, $56 \%$ of patients in the non-dehydrated group complained of fever and thus the fever could not be regarded as the specific sign of dehydration. In the dehydrated group, $44 \%$ of the patients died during the hospitalization, whereas $17 \%$ of the patients died in the non-dehydrated group. This result is similar to the previous report in 1991 that $50 \%$ of elderly Medicare beneficiaries hospitalized with dehydration died within a year of admission (7).

In the physical signs, dry mouth was the most frequently observed sign in all patients, but its specificity was low. The decreased skin turgor was also observed in many patients with low sensitivity (Table 2). Geriatric patients are prone to a loss of total body water and therefore, many dehydrated patients showed the lack of saliva production and decreased skin turgor.

Only dry axilla indicated moderate sensitivity and excellent specificity (Table 2). This result is similar to the previous report that dry axilla has 50\% sensitivity and $82 \%$ specificity, and both showed excellent specificity as a physical sign of dehydration. Dry axilla can be considered as a sign of dehydration. Decreased consciousness level and skin turgor showed a relatively low sensitivity with low odds ratios.

To determine the correlation between laboratory data and clinical diagnosis, we employed the common dehydration index such as TP, ALB, BUN/Cr, UA, $\mathrm{Na}^{+}$, and osmolality for blood tests, and $\mathrm{Na}^{+}, \mathrm{Cr}$, and osmolality for urine tests. $\mathrm{Na}^{+}$, and osmolality of the blood tests showed significant differences between the dehydrated and the non-dehydrated groups. On the other hand, all indexes for urine tests did not show any significant differences.

Furthermore, we examined the correlation between dry axilla and the common dehydration index described above (Table 4). For TP, ALB, BUN/Cr, and osmolality, there were significant differences between those with dry axilla and without dry axilla. TP for dry axilla was higher than that of wet axilla, but ALB for dry axilla was significantly lower than that of wet axilla. The reason why TP increased along with the decrease of ALB was thought that ALB was strongly affected by nutrition state as well as dehydration. The patients with dry axilla were speculated to be malnurished.

\section{Conclusion}

In conclusion, the present study demonstrated that the confirmation of the axillary moisture could indicate dehydration, as well as dehydration indexes such as serum sodium concentration, and osmolality. The dry axilla has the potentiality to be the simple method for detecting dehydration at home and in nursing homes.

The authors state that they have no Conflict of Interest (COI).

\section{References}

1. Eaton D, Bannister P, Mulley GP, Connolly MJ. Axillary sweating in clinical assessment of dehydration in ill elderly patients. BMJ 308: $1271,1994$.

2. Wotton K, Crannitch K, Munt R. Prevalence, risk factors and strategies to prevent dehydration in older adults. Contemporary Nurse 31: 44-56, 2008.

3. Wilson MM. The management of dehydration in the nursing home. J Nutr Health Aging 3: 53-61, 1999.

4. McGee S, Abernethy WB 3rd, Simel DL. The rational clinical examination. Is this patient hypovolemic? JAMA 281: 1022-1029, 1999.

5. Takehisa Y. Medical and care supporting hyper-aging society. Abstracts of the 18th congress of medical and care facilities 2010. Osaka, Japan, 2010-8-24/25. Japan Association of Medical and Care Facilities 1: 117-127, 2010.

6. Levitt MA, Lopez B, Lieberman ME, Sutton M. Evaluation of the tilt test in an adult emergency medicine population. Ann Emerg Med 21: 713-718, 1992.

7. Warren JL, Bacon WE, Harris T, McBean AM, Foley DJ, Phillips C. The Burden and outcomes associated with dehydration among US elderly. 1991. Am J Public Health 84: 1265-1269, 1994.

(C) 2012 The Japanese Society of Internal Medicine http://www.naika.or.jp/imindex.html 